\title{
Good Practices of Inclusive Education across India - A Study
}

\author{
Bharti Kaushik \\ DEGSN, NCERT \\ India
}

\begin{abstract}
Inclusion advocates diversification of the educational provisions and personalization of common learning experiences. This is in contrast to the traditional planning of the classroom activities, which is based on the "average" student. Inclusive education is all about building a support system, infusing flexibility in all dimensions of the schooling system, and its practices, so that needs of all stakeholders, are met. A GP is a practice that has been field-tested and has produced good results, and therefore recommended as a model. The states and UT's, across India, were adopting practices and strategies, as per the local context and needs, for implementing inclusive education, under SSA, and RMSA. Some of these locally adapted and innovated practices had the potential for adaptation and adoption by other states and UT's struggling to find solutions for similar problems and challenges. The questions were how to decide and choose which practice had this potential! The researcher developed a format and gathered 47 responses from the states and UT's about their practices for the implementation of inclusive education. Next, six-point criteria were prepared for the assessment of the reported GPs. Each one, of the 47 practices was assessed against this criterion. After the assessment, only 15 out of the 47 reported practices were found to satisfy the criteria of GP, and hence worthy of being called as GP. The present paper provides a brief description of these 15 GPs.
\end{abstract}

\section{Introduction}

"Inclusion is not a strategy to help people fit into the systems and structures which exist in our societies. It is about transforming those systems and structures to make it better for everyone. Inclusion is about creating a better world for everyone"

Diane Richler [1]

Education, a fundamental right, in the Constitution of India is also essential for recognition as a useful productive member of one's community and for participation in the community life in a meaningful way [2]. In the rapidly changing time, such as the present, one of the major aims of education is to address individual needs of all learners, including those with Special Educational Needs (SEN).

Inclusion advocates diversification of the educational provisions and personalization of common learning experiences [3, 4]. When done appropriately this facilitates the highest degree of participation of all students, irrespective of origin and degree of abilities and disabilities. This also implies movement towards the Universal Design of Learning (UDL). Principals of UDL, suggests that diversity in the needs of all learners is to be addressed from the beginning of the teaching-learning process, [5]. This is in contrast to the traditional planning of the classroom activities, which is based on the "average" student [6]. In other words, in traditional planning of teaching the activities are initially designed for 'average'. Afterward, appropriate individualized interventions are made to address the needs of specific students, left out of the original plan of activities which was prepared by the logic of homogeneity instead of diversity.

This brings 'inclusion' in the forefront. Inclusion in education implies that it is the responsibility of the society to change the environment so that the children with disabilities and disadvantages feel empowered to take part, on an equal basis, in the education system. Inclusion is concerned with the extent to which 'socially just', educational policy; pedagogy and teaching practice are being followed in schools and colleges [7].

In 2008, International Conference on Education, with the agenda of "Defining Inclusive Education" was organized by IBE, UNESCO [8]. The delegates of the conference reached the conclusion that diversity discourse is neither about students with disabilities or other special needs due to being immigrants or gifted nor it is about supporting teachers to carry out inclusive pedagogy practices. Inclusive education is all about building support system, infusing flexibility in all dimension of the schooling system and its practices, so that needs of all stakeholders, are met. 


\section{Understanding Good and Innovative Practices}

According to Webster Dictionary Good Practice (GP) is "wise thing to do" [9]. A GP is a practice that has been field tested, proven to work well and yielded good results, and so recommended as a model [10]. In laymen's words it is a repeated successful experience, which deserves to be shared for the benefit of masses.

The term GP is often used in the fields of health care, government administration, education system, project management, product development, and so on.

The word "innovation" is commonly associated with experiment, flexibility and fluidity, whereas word "good" often indicates contentment, context appropriateness and reliability. Both good practices and innovative practices encourage collaboration with relevant people, stakeholders and organisations.

Both good practices and innovative practices complement each other. Just as a good practice can be an innovative practice; an innovative practice can most certainly be good practice. However, there is a need to establish balance between the both.

\section{GP in the context of Inclusive Education}

Inclusion in education has been in practice in India for more than a decade. Initially, through inclusive education component under Sarva Shiksha Abhiyaan (SSA) [11] and later, under the Rashtriya Madhyamik Shiksha Abhiyaan (RMSA) [12], and currently it is an integral part of Samagra Shiksha [13]. The provisions for CWSN under Samagra Shiksha include, identification and assessment of children with disabilities, aids, appliances, medical services, diagnostic services, appropriate teaching learning material, transport and escort facilities, hostel, scholarships, support staff, large print textbooks, Braille books, uniform allowance, stipend for girl, use of ICT and awareness camps.

The states and UT's, across India were adopting practices and strategies, as per the local context and needs, for implementing inclusive education, under SSA, and RMSA. The relevant information was gathered from the states and UT's with the purpose of documenting good practices related to inclusive education under SSA and RMSA

\section{Methodology}

The research question, what innovative strategies adopted by states for implementing the IE provisions under SSA and RMSA, to resolve the local issues, such as scarcity of trained human resources, providing aids and appliances after need assessment and identification, addressing the special education needs within the mainstream schools etc., required developing the data collection format for gathering relevant information from States/UT's.
The developed data collection format was shared with all the States/UT's for inviting GP. Next the criteria for evaluating the GP were developed and each GP report obtained from states as data was assessed against defined criteria.

\subsection{Criteria for evaluating GP}

The criteria for evaluating GP defined by the researcher, was shared with the experts working in the field for their opinion and validation. The expert opinion facilitated finalization of the following criteria for the GP.

A practice can be said to be good only when, it -

1. has some newness/innovation

2. fulfills an existing need

3. has measurable effect

4. promotes collaboration among stakeholders

5. implements SSA/ RMSA/Samagra Shiksha provisions for CWSN, such as Curriculum Adaptation, Differentiated Instruction, adopting UDL based practices, transport allowance, stipend, teacher training etc.

6. is adaptable in other contexts and situations

\section{Data collection and sample}

All the states and UT's in India were contacted for sharing the information in the prescribed format hence the sample comprised of all the states and UT's. Only 19 states and UT's responded to the call and provided the desired information. Few states and UT's shared more than one practice. The researcher received 47 GP, out of these 45 were in paper pen and two were in audio-video format. Hence the data comprised of 47 reports of practices related with inclusive education.

\subsection{Analysis of findings}

Each practice was evaluated against the above mentioned criteria of GP with the help of experts in workshop mode. According to the criteria, the maximum marks possible were 6 , i.e. one mark per criteria point. The practices securing more than fifty percent marks were considered as GP.

The sub-sections below present the brief description of the 15 practices identified as good according to the criteria.

5.1.1. GP 1 Basic Coaches Training Program of Special Teacher (Haryana). Not all special teachers are aware of the rules and regulations of special games for students with disabilities. Realizing this gap in the implementation of inclusive education the state of Haryana collaborated with the Special Olympics Bharat and National Sports Federation, for training of 
the special teachers in basics of sports coaching. Financial help for this was sought from MHRD (Ministry of Human Resource and Development) Govt. of India. The impact of this practice could be observed in terms of quantitative and qualitative increase in the participation students with special needs in the sports and games activities. This in turn resulted in enhanced confidence and mental health of students with disabilities.

\subsubsection{GP 2 Coverage of Students with Disabilities,} through innovation in resource teacher deployment (Haryana). The goal of this practice was to reach each student with disabilities and ensure his/her participation in education. A special coverage plan was designed wherein one special teacher was available all the time at the resource room. This ensured effective utilization of resource room. This action plan was followed throughout the year. An observable effect of this practice was quantitative increase in the use of resource room by students with disabilities. Due to this the special teacher's deployed at the block level also felt more confident and appropriately supported while referring children with disabilities to resource room.

This practice found place in selected G.P due to the newness in the deployment strategies of special teachers, fulfillment of existing need, collaboration and adaptability in other context. This practice is also an example of optimum utilization of available resources.

\subsubsection{GP 3 Inclusive Adventures and Nature Study} Camp (Haryana). Students with disability conditions such as Intellectual Disabilities (Mild/Moderate), Orthopedic, Low vision, Hearing Impairment and Speech Impairment were provided the opportunity to take part in nature study camps. The students and the team of experts travelled by Volvo buses, to and fro the camp. Students with disabilities, studying in the state of Haryana, were able to observe the beauty of nature and enjoy adventure camp experience. This was considered as GP as it addressed an existing need, enhanced collaboration among stakeholders, promoted effective implementation of existing provision of the scheme and has adaptability in other contexts. The after effects of this were measurable in terms of retention of students and improvement in their attitude towards study and schooling.

\subsubsection{GP 4 Assembly in Sign Language} (Chhattisgarh). To build awareness about students with disabilities among teachers and students without disability, the state of Chhattisgarh, initiated organization of morning assembly in Sign Language. This enhanced social inclusion among children with and without disabilities through sign language. The measurable effect was increased sensitivities towards students with disabilities and their preferred mode of communication.

\subsubsection{GP 5 Identification of Non-Visual Disabilities such as LD (Chhattisgarh).} Identification of Non-Visual Disabilities such as Learning Disabilities (LD) was initiated as pilot project in the state of Chhattisgarh. The identification and assessment of students suspected of having LD was done with the help of trained psychologist and other experts, in the school premises. Appropriate support was provided to children identified with LD, in the form of need based adaptations in the curriculum and multi-sensory pedagogy practices.

5.1.6. GP 6 ICT based Education for Students with Visual Impairment (VI) (Rajasthan). In the state of Rajasthan, the children with VI were trained for autonomous use of computer in the classroom. This enabled them to take class notes and access online resources, independently. This was done by implementing a thoughtfully planned training program involving children with VI and support staff. The first step was to encourage independent reading of the digitally accessible textbooks. The other part of training focused on becoming familiar with the machine usage, its scope and maintenance. Introduction to QWERTY keyboards, screen reading software, installation and use of MS Office (MS word, excel etc.), Internet browsing, Web libraries, radio programs etc., were also part of the training curriculum. At the successful completion of the training program, 56 students with VI, received laptops, loaded with screen reading software-(NVDA in Indian accent), a headphone and a data card/device.

The functionaries involved in the implementation of this GP also conducted action research with the purpose of systematic follow-up and documentation of the effects and experiences for scaling up the practice. Local NGO, Sight Savers, collaborated with the state officials in this endeavor.

5.1.7. GP 7 Initiating TAB based ICT Training for Children with Visual Impairment (Madhya Pradesh). Children with VI in the state of Madhya Pradesh were trained in independent use of ICT devices, voice recorders, accessible libraries (Sugamya Pustakalaya), EPUB reading application, calculator, internet and E-resources etc. Smart phone (Samsung J2Pro) was provided to 27 children with VI, who completed the training successfully. The inclusive school authorities gave permission to these children to record classroom proceedings for later practice at home. This innovative strategy has shown improvements in students' academic performance in comparison with earlier academic years. 
5.1.8. GP 8 Public Private Partnership (Uttarakhand). Public Private Partnership (PPP) is an accepted mode of implementing government programs/schemes in partnership with the private sector. The term private in PPP encompasses all nongovernment agencies such as the corporate sector, voluntary organizations, self-help groups, partnership firms, individuals and community based organizations.

With this practice, the state of Uttarakhand intended to develop, well equipped, early intervention resource room for the children with special needs enrolled in the mainstream primary schools. This practice also aimed to offer early intervention and required therapeutic support to the children with disabilities enrolled in the home based education. As a result vertical mobility of children from home based education to education in neighborhood mainstream school became a possibility. The early intervention and therapeutic support received in the early intervention centers established in PP mode, led to prevention of further deterioration in the child's condition and facilitated the management of the condition, in holistic manner, by collaborating with parents and special teachers.

This idea of providing an early interventions center within the premises of existing primary schools is a new idea that addresses an existing need for therapy and promoting collaboration with other stakeholders. In addition this also has scope for scalability and adoption in other contexts.

5.1.9. GP 9 Self -defense Training (Odissa). The state of Odissa provided self-defense training was imparted to the adolescent girls. The basic principle of Self-defense is to lower the risks of becoming a victim. After the training the participant girls appeared to be more confident, emotionally and mentally better adjusted, and better prepared to deal with incidents requiring application of the skills learnt during self-defence training. This practice found place in the selected GP due to its focus on girls, fulfillment of existing need, better implementation of provision of the scheme, adaptability in other contexts and enhancing the collaboration among the stakeholders.

5.1.10. GP10 Education for Urban Deprived Children through Rescue and Rehabilitation (Odissa). Education deprived urban children in the age group 6-14 years were identified under this practice for the purpose of their rehabilitation in the new residential hostels as per the mandate of RTE Act 2009. This facilitated reduction in the number of out of school children and also supplemented the efforts of the parents living in difficult circumstances, towards education of their children.

Awareness campaign was organized in urban areas on regular basis with the involvement of previously rescued children, School Management
Committees (SMC), Cluster Resource Centre Coordinators (CRCC), Block Resource Centre Coordinators (BRCC), Inclusive Education (IE) Volunteers, teachers etc. These campaigns led to identification of children engaged in begging, child labor, orphans, children without adult protection, rag picking etc.

\subsubsection{GP 11 Program for Vision Screening and} Distribution of Spectacles to the School Students (Odissa). This GP was popularly known as, 'Bal Jyoti' among hoi-polloi. The state, in convergence with National Health Mission (NHM), District Blindness Control Society (DBCS), District Red Cross Society (IRCS), Chief District Medical Officer (CDMO) and Local Eye Hospitals, initiated vision screening and distribution of spectacles to the school students. The newness in the efforts was active involvement of regular teachers, in the process of initial identification. One teacher from, each participating school was trained in preliminary screening for identification of students with vision problem, by ophthalmic assistant of Primary Health Center (PHC) \& local eye hospital. Preliminary screening kit provided to the trained school teacher contained Snellen chart and other necessary screening material. After initial identification by the teacher the students were referred to the block level camp for further testing

This initiative resulted in identification of about 200 children with vision problem. In the identification camps not only the measurement for spectacle was taken but need based power spectacles were given, on the spot, to the students.

The children requiring additional eye treatment were referred to the district or state level eye hospital for advanced eye treatment, including the surgical correction.

\subsubsection{GP 12 Neuro- Regenerative Rehabilitation} Therapy (NRRT) - (Odissa). Neuro-Regenerative Rehabilitation Therapy (NRRT) uses combination of stem cell therapy and neuro- rehabilitation, to address the challenges faced due to neurological disorders such as autism, cerebral palsy, intellectual disability, muscular dystrophy, spinal cord injury, head injury, stroke, etc. The complete treatment involves stem cell therapy using adult stem cells, neurological and other treatments (using Neuro protective and other medications) and rehabilitation (including physiotherapy, occupational therapy, speech therapy, counseling, creative visualization etc.). The essential hospitalization period was 7 days.

Post NRRT treatment measurable effect includes enhanced attention span, better cognition, postural balance, and improvement in speech and muscle tone, better memory and improved social skills. 
5.1.13 GP 13 Early Learning Skills in Inclusive schools (Meghalaya). Teachers were trained and sensitized towards the needs of children with disabilities, and were encouraged to collaborate, and work together as a team, in implementation of Universal Design of Learning (UDL) based pedagogy practices in the early childhood care and education. Mairang Vidya Jyoti Inclusive School, in the state of Meghalaya was chosen as site of action for this practice. This school had one child with VI. This school had no Special Educator or any other teacher with specialization in VI.

This initiative has shown measurable effect in the acceptance of children with disability by teachers as well as peers along with enhancement in selfconfidence and academic skills.

\subsubsection{GP14 Assessments Camps and Distribution} of Hearing Aids on Same Day (Andhra Pradesh). The functionaries in the state of Andhra Pradesh attempted to identify school children with Hearing Impairments (HI) and to give them appropriate hearing aid without wasting time so that children can focus on their studies in the desired manner. During assessment camps, the team of expert assesses the students for hearing impairments \& speech impairments. The innovative aspect of this practice was identification of school children with Hearing Impairments (HI) and giving them appropriate hearing aid, along with orientation training towards the care and maintenance of hearing aids, on the same day.

This has resulted in improvement in the engagement and participation of children with $\mathrm{HI}$ in teaching learning activities at schools.

\subsubsection{G P. 15 Resource Room (RR) (Goa). This} Good practice was submitted by the state of Goa in audio visual format. The video revealed the smooth functioning of two RR in the same school.

One resource room was attempting to address the challenges faced due to learning disabilities and the other was promoting acquisition of life and vocational skills such as cookery, vegetable gardening, floriculture, horticulture and ICT. The former resource room was named as RR for students with learning disabilities and the later was called life skills RR.

\section{Discussion}

The 47 practices were reported by 19 states and UT's. The submitted practices could be majorly categorized into-- administrative (14), case studies (8), teacher training (5), co-curricular (4), awareness building (3), medical support (2), ICT integrated inclusive learning and IEP (2). The rest of the practices were related to distribution of aids and appliances, synergy generating, early identification and vocational training.

The inclusive education implementation practices reported by the states and UT's indicate lot of good work at the field level that often remains confined to only limited geographic area. These practices originated to address the local needs and were operational within the confines of the framework of Samagra Shiksha. The successful implementation of these practices in the Indian school education system indicates scalability potential of these practices.

The 15 practices selected as GP, were found to be more than the mere implementation of the provisions of Govt. schemes. These practices had the potential for up scaling, with appropriate adaptations as per the local context and found worthy of sharing due to their proven effectiveness.

\section{Conclusions}

The identification of select 15 GP can be considered as evidence that state functionaries have found their way to surmount the barriers in implementing the inclusive education provisions as defined in the scheme SSA and RMSA.

\section{References}

[1] Diane, R., (nd) Make the commitment- commit to inclusion http://committoinclusion.org/ (Access Date: 10 May, 2019).

[2] MHRD. (2010) 'Right to Education'; https://mhrd. gov.in/rte (Access Date: 3 February, 2019).

[3] UNICEF. (nd) 'Inclusive Education'; https://www.uni cef.org/education/inclusive-education (Access Date: 3 February, 2019).

[4] The Alliance for Inclusive Education, 'Definition Inclusive Education'; https://www.allfie.org.uk/definitions/ what-is-inclusive-education/ (Access Date: 3 February, 2019).

[5] CAST. (2018) 'Universal Design for Learning Guidelines'; http://udlguidelines.cast.org/ (Access Date: 7 February, 2019).

[6] TKI. (nd) 'Why UDL is valuable'; https://www.inclu sive.tki.org.nz/guides/universal-design-for-learning/whyudl-is-valuable/ (Access Date: 5 February, 2019).

[7] Heelan, A., (2015) 'Universal Design for Learning (UDL): Implications for Education'; https://arrow.tudublin. ie/cgi/viewcontent.cgi?article $=1000 \&$ context $=$ exdesthe 4 (Access Date: 4 February, 2019).

[8] UNESCO, IBE. (2008) 'International Conference on Education, session 48'; http://www.ibe.unesco.org/fileadmi n/user_upload/Policy_Dialogue/48th_ICE/Defining_Inclus ive_Education_Agenda_2009.pdf (Access Date: 28 December, 2018). 
[9] Merriam-Webster, https://www.merriam-webster.com/ dictionary/good\%20practice (Access Date: 31 May, 2019).

[10] FAO, (nd) 'Good Practices-An approach of experience capitalization'; www.fao.org/capacitydevelopment/ goodpractices/gphome/en/ (Access Date: 30 May, 2019).

[11] Nivedita, R., (2016) 'Standing Committee Report Summary-Implementation of SSA and Mid-Day Meal Scheme'; https://www.prsindia.org/sites/default/files/parlia ment_or_policy_pdfs/1483002992--SCR\%20Summary\%2 0SSA\%20and\%20MDMS.pdf (Access Date: 29 May, 2019).

[12] MHRD. (ND) 'Rashtriya Madhyamik Shiksha Abhiyaan'; https://mhrd.gov.in/rmsa (Access Date: 29 May, 2019).

[13] MHRD. (ND) 'Samagra Shiksha'; http://samagra.mhrd .gov.in/( Access Date: 29 May 2019). 